\title{
Notice of redundant publication
}

BMJ Case Reports wishes to inform its readers of the following redundant publication.

The publication:

Kulkarni VK, Deshmukh J, Banda NR, et al. Odontomas-silent tormentors of teeth eruption, shedding and occlusion. BMJ Case Rep. Published Online: 14 Dec 2012. doi: 10.1136/ bcr-2012-007666.

Considerably overlaps with the article:

Kulkarni VK, Vanka A, Shashikiran ND. Compound odontoma associated with an unerupted rotated and dilacerated maxillary central incisor. Contemp Clin Dent 2011;2:218-21.

The article in BMJ Case Reports has been retracted.

BMJ Case Rep 2013. doi:10.1136/bcr-2012-007666rp 